\title{
Resilience to infection by Mycobacterium avium subspecies paratuberculosis following direct intestinal inoculation in calves
}

\author{
Kevin J. Stinson, Monica M. Baquero and Brandon L. Plattner*
}

\begin{abstract}
Mycobacterium avium subspecies paratuberculosis (Map) is the cause of Johne's disease, a chronic enteritis of cattle. A significant knowledge gap is how persistence of Map within the intestinal tract after infection contributes to progression of disease. To address this, we exposed calves to Map by direct ileocecal Peyer's patch injection. Our objective was to characterize the persistence of Map in tissues, associated intestinal lesions, fecal Map shedding, and serum antibody responses, through the first 28-weeks post-inoculation (wpi). Previous work using this model showed 100\% rate of Map infection in intestine and lymph node by 12 wpi. We hypothesized that direct inoculation of Map into the distal small intestine would induce intestinal Map infection with local persistence and progression towards clinical disease. However, our data show decreased persistence of Map in the distal small intestine and draining lymph nodes. We identified Map in multiple sections of distal ileum and draining lymph node of all calves at 4 and 12 wpi, but then we observed reduced Map in distal ileum at 20 wpi, and by 28 wpi we found that $50 \%$ of animals had no detectable Map in intestine or the lymph node. This provides evidence of resilience to Map infection following direct intestinal Map inoculation. Further work examining the immune responses and host-pathogen interactions associated with this infection model are needed to help elicit the mechanisms underlying resilience to Map infection.
\end{abstract}

\section{Introduction}

Johne's disease (JD) is a chronic progressive enteric infection of cattle caused by the bacterium Mycobacterium avium subspecies paratuberculosis (Map). Susceptible animals, typically young calves, become infected by ingesting contaminated colostrum, milk, or feces [1]. Map invades the intestinal mucosa via $\mathrm{M}$ cells overlying Peyer's patches, where it is taken up by and replicates within resident macrophages. A potent inflammatory response drives recruitment of macrophages and development of granulomatous inflammation at the site of infection [2]. Infected animals then enter a lengthy subclinical period lasting up to 10 years; though these animals often show no clinical signs of infection for several years, they eventually shed Map via their feces into the environment and thus perpetuate its spread to susceptible herdmates [2,3]. Only a small portion of infected

*Correspondence: bplattne@uoguelph.ca

Department of Pathobiology, University of Guelph, Guelph, ON, Canada animals eventually progress to the invariably fatal clinical disease characterized by malabsorptive diarrhea due to chronic inflammation and thickening of the intestinal mucosa. Diseased animals experience decreased milk production, reduced reproductive efficiency, weight loss and wasting as clinical disease progresses [4]. The mechanisms underlying the early progression of intestinal Map infection remain underexplored and largely unknown.

It is difficult to estimate accurately the number of infected herds due to poor sensitivity of screening tests, especially in subclinical animals; however, it is estimated that in North America between 10 and $70 \%$ of herds have at least one Map-infected animal [5-7]. There is significant economic burden associated with JD of $\$ 250$ million USD per year in the United States alone, due to loss of productivity and early culling, though these estimates are nearly two decades old [8]. Subclinically diseased animals shed Map sporadically and clinically diseased animals shed Map progressively; both contribute to environmental 
contamination and exposure of susceptible calves to contaminated milk, colostrum, and feces [7, 9, 10]. Recent experimental models of calf-to-calf transmission indicated that $50 \%$ of contact-exposed animals showed demonstrable infection within 3 months of exposure [11]. Despite routine Map exposure, individual animal prevalence in endemic herds ranges between only $5-20 \%[5,6]$. Thus, a major question exists of why in endemic herds, where susceptible calves are routinely exposed to Map, do so few animals ever show evidence of disease? Whittington et al. [12] recently proposed the classification of "resilient" for susceptible animals exposed to Map, which show no signs of infection. It remains unclear if such resilience is derived primarily from improved mucosal barrier function, enhanced early pathogen clearance, other factors, or a combination of these factors.

The purpose of this study was to examine the early post Map-infection phase within the small intestine of calves to more fully understand persistence of Map in intestine and lymph nodes, and development of localized granulomatous lesions following direct experimental inoculation. Use of direct ileal Peyer's patch inoculation with a measured dose of Map allows for further exploration of localized intestinal Map infection in calves, an aspect of this disease that remains underexplored. The model has been shown to consistently induce enteric Map infection and is unique in its ability to reliably recapitulate the histologic lesions, patterns of fecal Map shedding, and immunologic responses consistent with natural subclinical JD [13]. Previous work utilizing this model has only examined the first 12 weeks post-experimental inoculation; thus, new work examining the progression of infection beyond 12 weeks is warranted, to help construct an improved understanding of early enteric Map infection.

This model is not intended to investigate the process of Map tissue invasion and infection, but instead attempts to recreate an established enteric infection through introduction of a measured dose of Map directly into the distal ileum. Studies using mathematical modelling for progression of JD following Map infection have shown that antigen load within the intestinal tissues plays a crucial role in driving progression from subclinical to clinical disease [14]. Therefore, our initial hypothesis was that calves directly inoculated with Map at the primary site of natural infection would develop persistent localized Map infection and then progress towards clinical disease. A more complete understanding of early progression of enteric Map infection with this model is likely to have significant impact on understanding and limiting naturally infections.

\section{Materials and methods}

\section{Bacterial strain and growth conditions}

The Map strain gc86 was used for inoculation in this study; this is a field strain isolated from the feces of a cow with clinical JD in Ontario, Canada [15]. This Map strain has been utilized for a number of JD studies, both in vitro and in vivo [16-19]. Prior to each surgical inoculation, a frozen stock of Map gc86 was recovered into Middlebrook 7H9 broth (Becton-Dickinson, Oakville, Ontario, Canada) supplemented with 10\% OADC (oleic acid, albumin, dextrose, catalase; Becton-Dickinson Canada), 0.05\% Tween 80 (Sigma-Aldrich, Oakville, Ontario, Canada), and $2 \mathrm{mg} / \mathrm{L}$ Mycobactin J (Allied Monitor Inc, Fayette, Missouri, USA), and then grown in a stationary flask at $37^{\circ} \mathrm{C}$ with $5 \% \mathrm{CO}_{2}$. Colony forming units were approximated by measuring light absorbance using spectrophotometry at $540 \mathrm{~nm}$ and comparison to a previously described standard curve (validated for use with gc 86 by confirmation with quantitative culture) $[13,20,21]$.

\section{Inoculum preparation}

Following quantification, the Map for inoculation of calves was collected by centrifugation of $6 \times 10^{9} \mathrm{CFU}$ of Map at $1500 \times g$ for $20 \mathrm{~min}$. The bacterial pellet was resuspended in $1.5 \mathrm{~mL}$ of sterile phosphate-buffered saline (PBS) to a final concentration of $1 \times 10^{9} \mathrm{CFU}$ per $250 \mu \mathrm{L}$, and briefly pulse sonicated to disperse bacterial clumps (confirmed via microscopy, and flow cytometry scatter plot). Tuberculin syringes were loaded with $250 \mu \mathrm{L}$ (representing a total of $10^{9} \mathrm{CFU}$ Map) of inoculum and stored at $4{ }^{\circ} \mathrm{C}$ until time of surgery (within $12 \mathrm{~h}$ of preparation).

Prior to inoculation, the viability of the Map contained within inoculum was determined by fluorescein diacetate (Sigma-Aldrich) staining, with analysis by flow cytometry, as previously described [18, 22]. A minimum of $90 \%$ viability of Map was confirmed prior to animal inoculation.

\section{Animal trial design}

Castrated male Holstein calves between 3 and 4 weeks old were sourced from the University of Guelph Elora dairy research and teaching farm, a farm considered Johne's disease free based on voluntary participation in a Johne's disease surveillance program. There have been no cases of clinical Johne's disease for over 15 years and continuous negative on herd and individual animal level by regular milk and serum ELISA testing. Calves were transported to and housed for the duration of the experiment in an animal biosafety level 2 facility on the main campus of the University of Guelph in Guelph, Ontario. Based upon animal welfare concerns, calves were cohoused in groups of two or four animals per room, with uninfected animals housed separately in dedicated 
control rooms. Personnel entering the rooms donned clean coveralls, boots, surgical mask, hairnet, and gloves within the antechambers of each animal room. Re-entry into rooms housing control animals was not permitted following contact with Map-exposed animals, to eliminate the risk of cross contamination. Animals were maintained on standard non-medicated diets for the duration of the study.

A total of 24 calves were used for this experiment. Calves were randomly assigned into four groups based on pre-determined termination/euthanasia time points and calf availability. Each group contained two control and four Map-exposed calves. A 1-week period was given to all calves after arriving into the animal housing facility to allow for environmental acclimation and to ensure health prior to Map inoculation. Calves were euthanized by intravenous barbiturate overdose according to their pre-assigned groups, by time following Map inoculation: $4,12,20$, or 28 wpi. All live animal research protocols for this study were pre-approved by the University of Guelph Institutional Animal Care Committee.

\section{Surgical Map inoculation}

Calves were inoculated with live Map using a surgical inoculation method previously described [13]. Briefly, a $10-\mathrm{cm}$ skin incision was made in the right paralumbar fossa and then extended through the abdominal wall muscle and peritoneum into the abdominal cavity. The distal ileum and cecum were exteriorized, the Peyer's patches of the distal ileum were visually identified, and then $1 \times 10^{9} \mathrm{CFU}$ live Map in PBS was injected into the subserosal Peyer's patch rich region on the anti-mesenteric surface of the distal ileum. Following Map injection, $250 \mu \mathrm{L}$ of sterile diluted India ink was subserosally injected into the distal ileum approximately $5 \mathrm{~cm}$ proximal to the site of Map injection in order to facilitate localization of the Map-inoculation site during tissue collection at post-mortem examination. The distal ileum was then replaced into the abdomen prior to closure of the muscle and skin incisions using standard suture pattern and technique. Calves were not administered antibiotics at any point during the study. A single therapeutic dose $(0.5 \mathrm{mg} / \mathrm{kg}$ body weight, by intramuscular injection) of meloxicam was administered immediately after surgical Map-inoculation and the incision site was treated with topical povidone-iodine to reduce the risk of secondary bacterial infection at the surgical site. No major complications were observed in any calf after surgical inoculation of Map. Some animals developed mild localized inflammation at the incision site in the week following surgery; these wounds were treated topically using antiseptic solution until proper healing occurred.

\section{Feces and blood collection}

Feces were collected per rectum prior to Map inoculation and bi-weekly thereafter until the end of the study. Feces were immediately stored in $15 \mathrm{~mL}$ cryovials at $-80^{\circ} \mathrm{C}$ until processing. Serum was collected into serum separator tubes via jugular venipuncture prior to Mapinoculation and monthly thereafter. Serum was separated from cells and stored at $-80^{\circ} \mathrm{C}$ until processing.

\section{Euthanasia, post-mortem examination and tissue collection}

Calves were euthanized by intravenous barbiturate overdose, and a thorough post-mortem examination was performed immediately following euthanasia. Four segments of the distal small intestine including ileocecal valve (A), and three sections of ileum proximal to the ileocecal valve at $5 \mathrm{~cm}$ intervals $(\mathrm{B}-\mathrm{D})$, all of which contained both Peyer's patch and non-Peyer's patch regions, and the ileocecal (draining) lymph node were collected. Serial sections of each intestine and lymph node tissue samples described above were preserved in $10 \%$ neutral buffered formalin for histologic assessment, snap frozen in OCT compound, and snap frozen in cryovials for storage at $-80^{\circ} \mathrm{C}$.

\section{Histologic lesion scoring}

After $24 \mathrm{~h}$ immersed in 10\% neutral buffered formalin, tissues were trimmed for size, placed into cassettes, dehydrated, and embedded in paraffin. Serial sections were cut at $8 \mu \mathrm{m}$ and then stained by routine hematoxylin and eosin (H\&E) and Ziehl-Neelsen (ZN) according to standard protocols in the Animal Health Laboratory (Lab Services Division, University of Guelph). All tissue sections were visually scored for inflammation as described below, and all $\mathrm{ZN}$-stained sections were scored for the presence or absence of acid-fast bacilli (AFB) by a board-certified veterinary pathologist (BLP), who was blinded to calf ID, experimental Map inoculation status and time point after Map inoculation of calves for each tissue at the time of scoring.

The scoring system for inflammation in the intestine and draining lymph node (Table 1) was modified slightly from several previously published scoring systems in ruminant JD studies [23-25]. Briefly, scores from 0 to 5 were assigned based on the severity and distribution of granulomatous inflammation in each tissue section individually. Scores ranged from a minimum of 0 (no lesions, histologically normal) to a maximum of 5 (severe coalescing to diffuse granulomatous inflammation in the intestinal mucosa or lymph node parenchyma and extending into the submucosa of the small intestine or into afferent or efferent lymphatics of the node). Representative 
Table 1 Scoring system for identification of histologic lesions by H\&E staining

\begin{tabular}{ll}
\hline Score & Definition \\
\hline $0^{\text {a }}$ & None \\
$1^{\text {b }}$ & $\begin{array}{c}\text { Focal granulomatous inflammation (lamina propria or subcorti- } \\
\text { cal sinus, cortex only) }\end{array}$ \\
$2^{c}$ & $\begin{array}{c}\text { Multifocal to coalescing granulomatous inflammation (lamina } \\
\text { propria or subcortical sinus or cortex only) }\end{array}$ \\
3 & Coalescing/diffuse granulomatous inflammation (lamina propria, \\
& subcortical sinus, cortex) \\
$4^{\text {d }}$ & Coalescing/diffuse granulomatous inflammation (extending into \\
& submucosa or medulla) \\
5 & Coalescing/diffuse lesions extending deeply into submu- \\
cosa \pm lymphangitis
\end{tabular}

a Scores of 0 were classified as within normal limits.

b Scores of 1 were classified as mild lesions.

c Scores of 2-3 were classified as moderate lesions.

d Scores of 4-5 were classified as severe lesions.

images illustrating the scoring system are shown in Figure 1. Given the range of inflammatory cells in the intestine of normal calves and for the purpose of this study, lesion scores of 0 were considered within normal limits. Scores of 1 were defined as mild lesions, scores of 2-3 were defined as moderate lesions, and scores of $4-5$ were defined as severe lesions.

\section{Tissue DNA extraction}

DNA was extracted from all intestinal and lymph node tissue samples (five samples per calf, tissues A-E as described above) using the DNEasy Blood and Tissue Kit (Qiagen, Toronto, Ontario, Canada), with several modifications. Briefly, $100 \mathrm{mg}$ of frozen tissue per site, compared to $20 \mathrm{mg}$ standard in commercial tissue DNA extraction kits, was digested in $360 \mu \mathrm{L}$ of buffer ATL and $40 \mu \mathrm{L}$ of proteinase $\mathrm{K}$ overnight at $56{ }^{\circ} \mathrm{C}$ with mixing at $1000 \mathrm{RPM}$ on a Thermomixer (Eppendorf Canada, Mississauga, Ontario, Canada). Cell lysis was performed in $400 \mu \mathrm{L}$ of buffer $\mathrm{AL}$ at $95{ }^{\circ} \mathrm{C}$ for $5 \mathrm{~min}$. DNA was precipitated with $400 \mu \mathrm{L}$ of ice cold $100 \%$ ethanol at $-20{ }^{\circ} \mathrm{C}$ for $5 \mathrm{~min}$. The entire sample volume was then loaded onto spin columns in two stages (600 $\mu \mathrm{L}$ at a time), which was followed by two wash steps (each) with buffers AW1 and AW2. DNA was eluted with $50 \mu \mathrm{L}$ of buffer $\mathrm{AE}$, and stored at $-80{ }^{\circ} \mathrm{C}$ for downstream processing. Every tissue section which tested negative by PCR (described below), was re-extracted and re-processed, to maximize sensitivity of the diagnostic assay.

\section{Fecal DNA extraction}

Fecal samples for DNA extraction were first subjected to a pre-treatment technique modified from the
Mississippi Veterinary Research and Diagnostic Laboratory, with the goal of reducing normal fecal microbiota and increased sensitivity for detection of Map [26]. Briefly, $1 \mathrm{~g}$ of frozen feces was thawed and diluted in $17.5 \mathrm{~mL}$ of pre-lysis buffer (30 mM Tris-HCL pH 8, $0.02 \mathrm{~N} \mathrm{NaOH}, 0.1 \%$ SDS; final $\mathrm{pH}$ 9.65), vortexed for $30 \mathrm{~s}$, and allowed to settle for $30 \mathrm{~min}$. The top $15 \mathrm{~mL}$ of supernatant was collected and transferred to a new tube, then pelleted by centrifugation at $1500 \times g$ for $20 \mathrm{~min}$. This pellet obtained after pre-treatment was used as the starting point for the DNA extraction using the Stool DNA isolation kit (Norgen Biotek, Thorold, Ontario, Canada). Briefly, DNA was extracted according to the manufacturer's recommendation, with inclusion of an optional 10 -min incubation at $65^{\circ} \mathrm{C}$ following pellet resuspension in Lysis Buffer $\mathrm{L}$ and Lysis Additive A, prior to bead beating at $30 \mathrm{~Hz}$ for $1 \mathrm{~min}$ (TissueLyser II, Qiagen, Toronto, Ontario, Canada).

\section{Map PCR}

Map was detected by PCR using a two-step heminested PCR reaction for the Map IS900 element. Accustart PCR Toughmix II (Quanta Biosciences, Beverly, Massachusetts, USA) was used as the PCR master mix, with the addition of $2.5 \mu \mathrm{g}$ of molecular grade bovine serum albumin. Both rounds of PCR utilized the same cycling conditions, consisting of a 5-min initial denaturation step at $95{ }^{\circ} \mathrm{C}$ followed by 35 cycles of: $30 \mathrm{~s}$ at $95{ }^{\circ} \mathrm{C}, 30 \mathrm{~s}$ at $68{ }^{\circ} \mathrm{C}$, and $60 \mathrm{~s}$ at $72{ }^{\circ} \mathrm{C}$. This was followed by a final 5 -min extension at $72{ }^{\circ} \mathrm{C}$. Products were then loaded onto a $1 \%$ agarose gel in a TrisEDTA-Acetic acid buffer, and stained using ethidium bromide. The first round of PCR utilized the forward primer IS900.F1 (5'-CTGGAGTTGATTGCGGCG G-3'), and the conserved reverse primer IS900.R (5'TGGTTGCGGGGTGGTAGAC-3') for a 1064 base pair product. The second round of PCR utilized the forward primer IS900.F2 (5'-GATGCGCCACGACTTGCAG-3') and IS900.R, for an 839 base pair product.

\section{Validation of molecular assays}

PCR primers were designed based on sequence alignment of IS900 and non-Map IS900-like elements, available on NCBI GenBank, and targeted to regions conserved in Map sequences, but not in non-Map sequences. Primers were also selected with a high annealing temperature $\left(68{ }^{\circ} \mathrm{C}\right)$, to reduce the risk of non-specific priming. Together, these factors help reduce the risk of low specificity often attributed to nested PCR methods. The primers were validated 


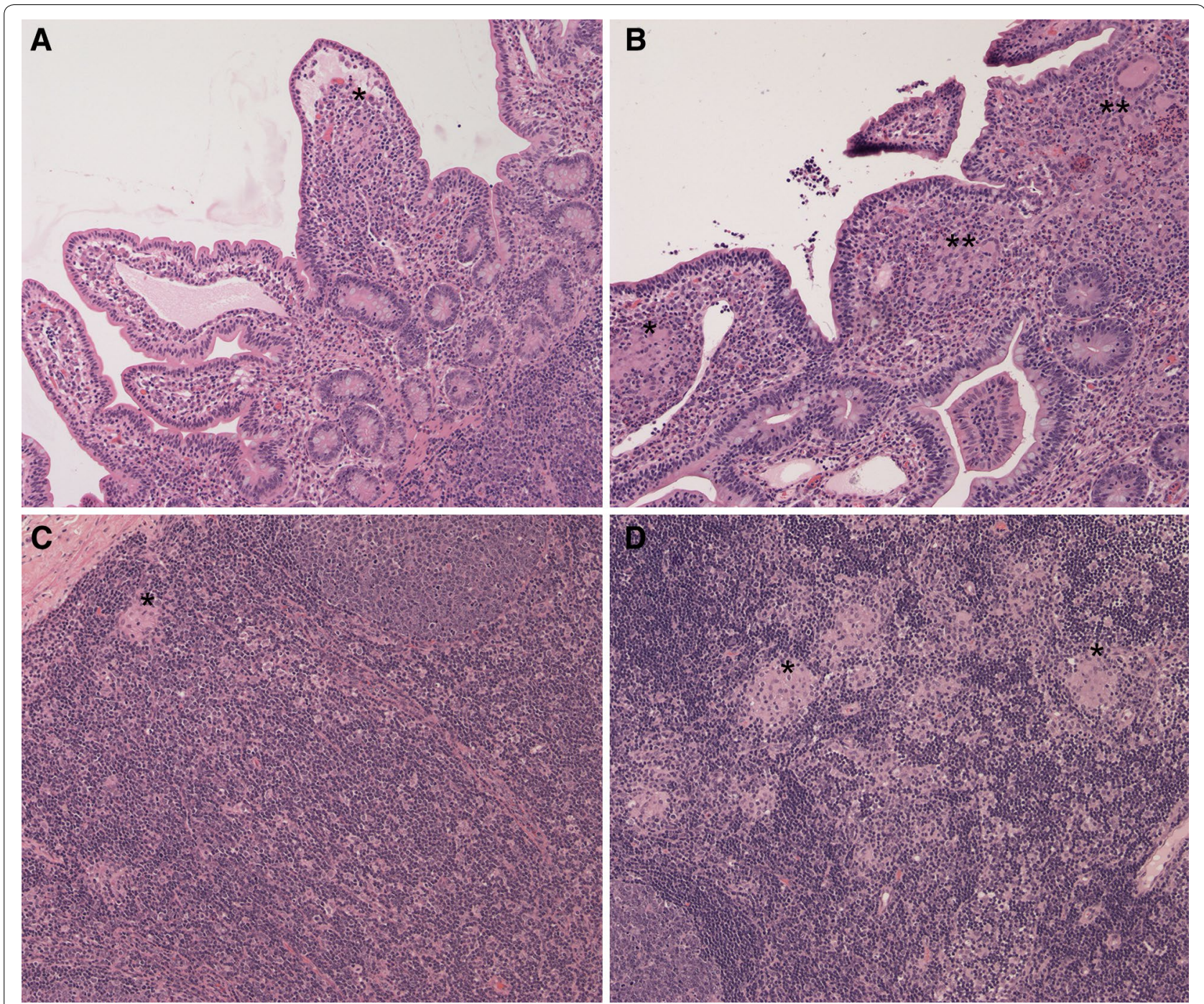

Figure 1 Histologic lesions identified in small intestine and lymph node. A is ileum, score $=1$ due to focal granulomatous inflammation with multinucleated giant cells $(*) ; \mathbf{B}$ is ileum, score $=3$ due to coalescing granulomatous inflammation in lamina propria $\left(^{*}\right)$ and submucosa (not shown), with multinucleated giant cells $\left(^{* *}\right)$; $\mathbf{C}$ is lymph node cortex, score $=1$, due to focal granulomatous inflammation in the subcapsular cortex $(*)$; and $\mathbf{D}$ is lymph node cortex, score $=3$ due to coalescing granulomatous inflammation in subcapsular cortex $\left(^{*}\right)$ and extending throughout the node (not shown). All images are H\&E stained, viewed at 100x magnification.

against Map gc86 using a serial dilution of DNA, with repeatable detection down to $0.025 \mathrm{pg} / 5 \mu \mathrm{L}$, and occasional detection down to $0.0025 \mathrm{pg} / 5 \mu \mathrm{L}$ (approximately 5 and 0.5 genomic equivalents respectively, based upon 4830000 base pairs). The primers were tested against Map K10, and Mycobacterium smegmatis, with positive detection of $\mathrm{K} 10$ and no detection of M. smegmatis. Agarose gel analysis showed one or two bands (two bands present in higher DNA concentrations only), which Sanger sequencing identified as first and second round PCR products. As a comparison, the same serial dilution was run on the Vet Alert commercial Map qPCR assay (Tetracore, Rockville, Maryland, USA), with reliable detection to the same lower limit of five genomic equivalents.

To further evaluate the PCR assay, and to validate the tissue DNA extraction, DNA was extracted from two segments of intestinal tissue (ileum) and one segment of lymph node taken from a cow diagnosed with clinical JD (based upon clinical presentation, histopathologic lesions). The hemi-nested PCR assay, combined with the tissue DNA extraction method described here, was able 
to detect Map in these tissues down to a $1 / 100000$ dilution, while the same dilution series using the Tetracore qPCR kit showed detection only to $1 / 10000$.

Lastly, fecal DNA extraction was validated by spiking feces with a serial dilution of Map gc86, with repeatable detection to a dilution of approximately $5 \mathrm{CFU} / \mathrm{g}$ (CFU approximate, determined by spectrophotometry).

\section{Serum ELISA}

Map-specific serum antibodies were measured in individual calf sera collected just prior to euthanasia, using a commercially-available Map antibody ELISA assay (IDEXX Canada, Markham, Ontario, Canada) at the Animal Health Laboratory, University of Guelph. The IDEXX Map antibody ELISA test determines seropositivity of individual samples based on the sample:positive control absorbance ratio (S/P). Samples with an S/P ratio below 0.45 were considered negative, while an $\mathrm{S} / \mathrm{P}$ ratio above 0.55 was considered positive. An S/P ratio between 0.45 and 0.55 was considered suspect, according to the assay's guidelines.

\section{Animal infection status}

Animals were defined as exposed, infected, diseased, or resilient based upon clinical case definitions described by Whittington et al. [12]. All animals that underwent surgical Map inoculation were considered Map-exposed. Calves with positive detection of Map in tissues either by PCR or by ZN staining, were considered Map infected. Animals with Map-induced histologic lesions in ileum and/or lymph nodes were considered diseased. Finally, Map-exposed animals but with no Map detected in tissues at the time of euthanasia, were considered resilient to Map infection. Fecal shedding and presence of Mapspecific serum antibodies were not included in defining animal infection status, due to the possibility of transient fecal shedding in either unexposed or resilient uninfected animals, or development of antibody responses in resilient animals, as demonstrated in a recent sheep infection study [27].

\section{Statistical inference}

Statistical significance was calculated using R Studio, by generalized linear mixed effect regression modelling using the lme4 package's "glmer" function. Modelling was designed to examine number of PCR positive tissues by timepoint (logistic regression), number of $\mathrm{ZN}$ positive tissues by timepoint (logistic regression), and mean histologic lesion scores by time point (poisson distribution). Animal ID and tissue ID were included as nested random effects, and timepoint as a fixed effect with slope and intercept dependent on animal ID and tissue ID. The general formula for this regression was: FACTOR $\sim$ timepoint + (timepoint|animal/tissue), where FACTOR represents PCR data, ZN data, or histologic lesion scores [28]. Significance was reported as odds ratios with a significance level of $\alpha=0.05$. Marginal effects plots were generated using the sjPlot's "plot_model" function for models which reported significant odd's ratios.

\section{Results}

\section{Gross lesions}

At post-mortem examination, the location of initial Map inoculation site in each calf was confirmed visually based on the presence of India ink. Ink was observed in Peyer's patches region of the distal ileum $5-8 \mathrm{~cm}$ proximal to the ileocecal valve, and frequently in the draining ileocecal lymph node of Map-exposed calves. Ileocecal lymph node enlargement was observed in some Map-exposed calves; however, lymph node size was variable between calves and not significantly different between Mapexposed and control calves. Some calves had fibrous adhesions between the serosal surface of the distal ileum and the omentum or rarely the parietal peritoneum; however, the small intestinal mucosa in all calves was grossly normal and significant gross lesions attributable to Map infection were not observed in any animal.

\section{Histologic lesions and scoring}

Histologic lesions, lesion scores, and the presence of AFB in intestinal and lymph node segments, respectively, are shown in Figures 1 and 2 with a data summary in Table 2. No calves in control groups (not Map-exposed) had evidence of granulomatous inflammation or AFB in any tissues at any time-point in this study. Within the small intestine, granulomatous inflammation attributed to Map and AFB were observed predominantly within the lamina propria. The maximum score for granulomatous inflammation in any intestine or lymph node tissue segment in this study was 3 .

Experimentally Map-inoculated calves in the 4 wpi group had mild $(n=3)$ or moderate $(n=2)$ granulomatous inflammation in $25 \%(5 / 20)$ of all tissue segments. The maximum lesion score observed was $2(n=2)$ with a mean lesion score of 0.35 (95\% CI of 0.05-0.64). Acid fast bacteria were directly observed following $\mathrm{ZN}$ staining in $15 \%(3 / 20)$ of tissue segments.

At 12 wpi, granulomatous inflammation was observed in 55\% (11/20) of all tissue segments from Map-exposed animals, with eight mild lesions, and three moderate lesions. The maximum lesion score was $3(n=3)$, with a mean lesion score of 0.85 (95\% CI of $0.39-1.31)$. Acid fast 

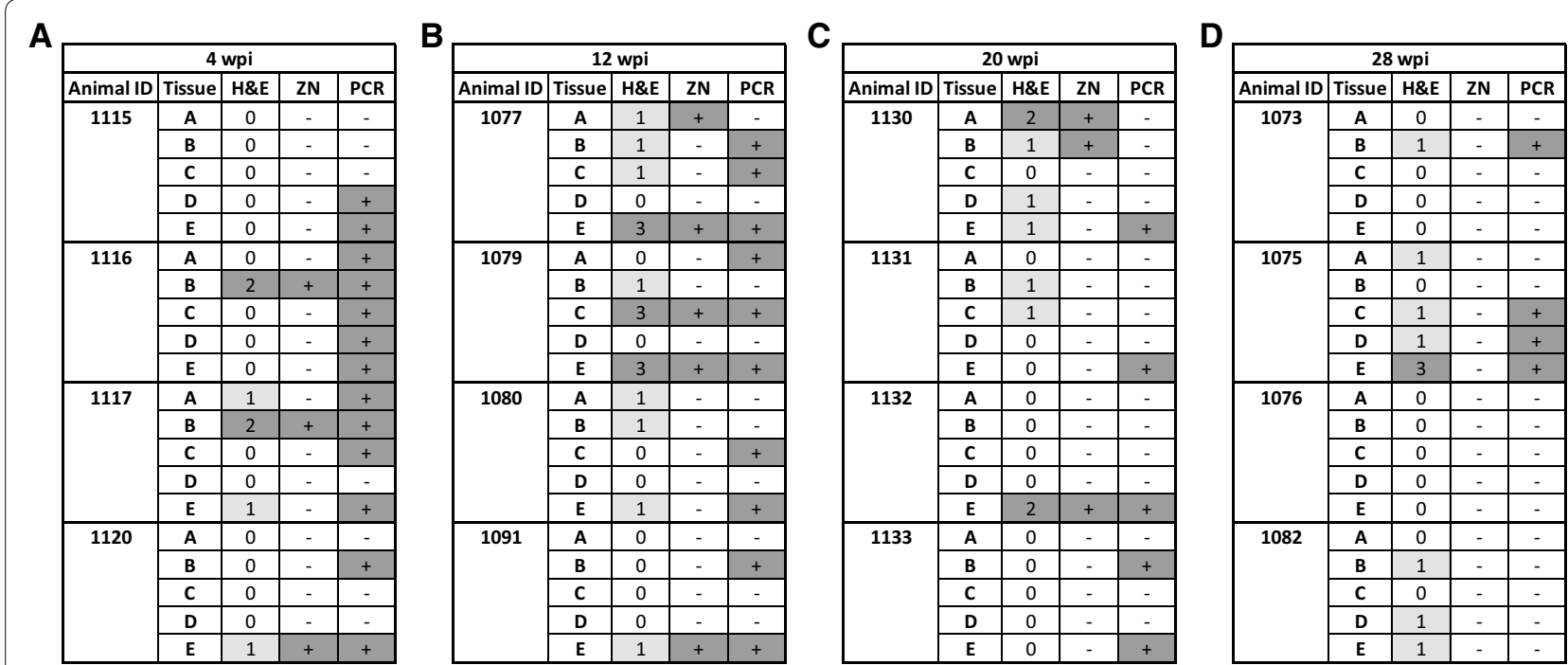

Figure 2 Lesion scores, ZN, and PCR results for Map-exposed calves, by weeks post-inoculation (wpi). Histologic lesions were classified as negative if no lesions were detected, mild (light gray) for lesion scores of 1, or moderate (dark gray) for lesion scores of 2 and 3. No severe histologic lesions were observed. ZN data shows detection of acid fast bacilli (dark gray). Lastly, PCR shows detection of Map DNA in tissue by PCR (dark gray). Time points were 4 (A), 12 (B), 20 (C), and 28 (D) wpi, examining four ileal tissues (A-D), and the draining ileocecal lymph node (E).

Table 2 Summary of histologic lesion scores (H\&E) and acid fast bacteria (ZN) positive tissues by infection group (timepoint)

\begin{tabular}{lllllll}
\hline $\begin{array}{l}\text { Infection group } \\
\text { (wpi) }\end{array}$ & \# mild lesions & $\begin{array}{l}\text { \# moderate } \\
\text { lesions }\end{array}$ & \# severe lesions & $\begin{array}{l}\text { Mean lesion score } \\
\mathbf{9 5 \%} \mathbf{C l})\end{array}$ & $\begin{array}{l}\text { Maximum lesion } \\
\text { score }\end{array}$ & \# ZN positive \\
\hline 4 & 3 & 2 & 0 & $0.35(0.05-0.64)$ & 2 & 3 \\
12 & 8 & 3 & 0 & $0.85(0.39-1.31)$ & 3 & 5 \\
20 & 5 & 2 & 0 & $0.45(0.15-0.75)$ & 2 & 3 \\
28 & 7 & 1 & 0 & $0.5(0.17-0.83)$ & 3 & 0 \\
\hline
\end{tabular}

bacteria were directly observed following $\mathrm{ZN}$ staining in $25 \%(5 / 20)$ of tissue segments.

At 20 wpi, granulomatous inflammation was observed in 35\% (7/20) of all tissue segments from Map-exposed animals, with five mild lesions, and two moderate lesions. The maximum lesion score was $2(n=2)$, with a mean lesion score of 0.45 (95\% CI 0.15-0.75). Acid fast bacteria were directly observed following ZN staining in $15 \%$ $(3 / 20)$ of tissue segments.

Finally, at $28 \mathrm{wpi}$, granulomatous inflammation was observed in $40 \%(8 / 20)$ of all tissue segments from Mapexposed calves, with seven mild lesions, and one moderate lesion. The maximum lesion score was $3.0(n=1)$, with a mean lesion score of 0.5 (95\% CI $0.17-0.83)$. Acid fast bacteria were not directly observed following $\mathrm{ZN}$ staining in any of the tissue segments from animals in this time group.

Statistical analysis of tissue inflammation scores and the number of tissues with observed AFB following $\mathrm{ZN}$ staining were not significantly different between timepoints. Tissue inflammation scores had an odds ratio of 1.22 (95\% CI $0.78-1.91, P=0.386$ ), while $\mathrm{ZN}$ positive tissues had an odds ratio of 0.61 (95\% CI 0.33-1.14, $P=0.120)$.

\section{Tissue PCR}

Map specific tissue PCR data are shown in Figure 2. At all timepoints in this study, no intestine or lymph node tissue segments from control (not Map-exposed) calves tested positive for Map by PCR.

At $4 \mathrm{wpi}$, Map-exposed animals were positive for Map by PCR in $65 \%(13 / 20)$ of intestine and lymph node tissue segments. All calves in the 4 wpi group tested positive for Map by PCR in two or more intestinal or lymph node tissue segments. At 12 wpi, Map-exposed calves were positive for Map by PCR in 50\% (10/20) of tissue segments. All Map-exposed calves at 12 wpi tested positive for Map by PCR in two or more sections of intestine or lymph node. At 20 wpi, Map-exposed calves were positive for 
Map by PCR in 25\% (5/20) of tissue segments. All calves at this time point tested positive for Map by PCR in at least one tissue, and only one animal tested positive in two tissues. Finally, for calves euthanized at 28 wpi, $20 \%$ $(4 / 20)$ of all tissue segments were positive for Map by PCR. Only two calves in the 28 wpi group tested positive for Map by PCR in at least one tissue segment: one calf tested positive for Map by PCR in a single segment of small intestine, and the other calf was positive for Map by

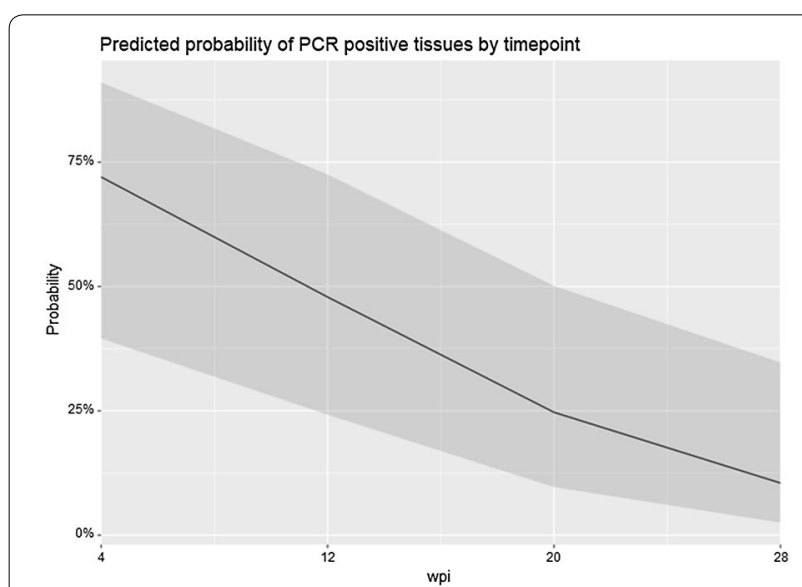

Figure 3 Marginal effects plot of the PCR statistical model, depicting the probability of PCR positive tissues as a factor of timepoint. The calculated probability is depicted as the solid line, with the confidence interval depicted as the shaded region. The statistical model identified a significant effect of time on the probability of $P C R$ positive tissues, with an overall odd's ratio of 0.36 (95\% Cl 0.18-0.70, $P=0.003$ ).
PCR in two segments of small intestine and the draining ileocecal lymph node. The remaining two Map-exposed animals in the 28 wpi group were negative in all tissue segments tested, despite repeated extraction and processing of DNA from all segments of tissue negative for Map by PCR, as described above.

Analysis of Map positive tissue segments at each time point identified statistically significant differences between study groups. The logistic model calculated an odds ratio of 0.36 ( $95 \% \mathrm{CI} 0.18-0.70, P=0.003$ ), suggesting a significant protective effect of time on the probability of Map positive tissue segments by PCR (Figure 3).

\section{Fecal Map PCR}

Bi-weekly fecal Map PCR data for all animals are shown by time point in Figure 4. Shedding of Map in the feces of control calves (not Map-exposed) was not detected in this study. Map shedding in the feces of Map-exposed calves was detected only sporadically throughout this study. As shown in Figure 4A, the 4 wpi group had no detected instances of Map shedding in the feces of Mapinoculated calves. In the 12 and 20 wpi groups (Figures $4 \mathrm{~B}$ and $\mathrm{C}$, respectively), Map shedding in the feces was detected in $50 \%(2 / 4)$ of the Map-exposed animals, but only at two individual time points; intermittent fecal shedding of Map in the feces was not detected in these groups. At 28 wpi (Figure 4D), shedding of Map in the feces was detected in $75 \%(3 / 4)$ of the animals, and each individual calf shed Map in the feces on multiple

\begin{tabular}{|c|c|c|c|c|c|c|c|c|c|c|c|c|c|c|c|c|}
\hline \multirow[t]{5}{*}{$\mathbf{A}$} & Animal ID & Pre & $2 \mathrm{wpi}$ & $4 \mathrm{wpi}$ & $6 \mathrm{wpi}$ & $8 \mathrm{wpi}$ & $10 \mathrm{wpi}$ & $12 \mathrm{wpi}$ & 14 wpi & $16 \mathrm{wpi}$ & $18 \mathrm{wpi}$ & 20 wpi & $22 \mathrm{wpi}$ & $24 \mathrm{wpi}$ & $26 \mathrm{wpi}$ & $28 \mathrm{wpi}$ \\
\hline & 1115 & - & - & - & N/A & N/A & N/A & N/A & $\mathrm{N} / \mathrm{A}$ & N/A & N/A & N/A & $\mathrm{N} / \mathrm{A}$ & N/A & N/A & $\mathrm{N} / \mathrm{A}$ \\
\hline & 1116 & - & - & - & N/A & N/A & $\mathrm{N} / \mathrm{A}$ & $\mathrm{N} / \mathrm{A}$ & N/A & $\mathrm{N} / \mathrm{A}$ & N/A & $\mathrm{N} / \mathrm{A}$ & N/A & N/A & N/A & $\mathrm{N} / \mathrm{A}$ \\
\hline & 1117 & - & - & - & $\mathrm{N} / \mathrm{A}$ & $\mathrm{N} / \mathrm{A}$ & $\mathrm{N} / \mathrm{A}$ & N/A & $\mathrm{N} / \mathrm{A}$ & $\mathrm{N} / \mathrm{A}$ & $\mathrm{N} / \mathrm{A}$ & $\mathrm{N} / \mathrm{A}$ & N/A & N/A & N/A & $\mathrm{N} / \mathrm{A}$ \\
\hline & 1120 & - & - & - & N/A & N/A & N/A & N/A & $\mathrm{N} / \mathrm{A}$ & $\mathrm{N} / \mathrm{A}$ & $\mathrm{N} / \mathrm{A}$ & $\mathrm{N} / \mathrm{A}$ & $\mathrm{N} / \mathrm{A}$ & N/A & $\mathrm{N} / \mathrm{A}$ & $\mathrm{N} / \mathrm{A}$ \\
\hline \multirow[t]{5}{*}{ B } & Animal ID & Pre & $2 \mathrm{wpi}$ & $4 \mathrm{wpi}$ & $6 \mathrm{wpi}$ & $8 \mathrm{wpi}$ & $10 \mathrm{wpi}$ & $12 \mathrm{wpi}$ & 14 wpi & $16 \mathrm{wpi}$ & $18 \mathrm{wpi}$ & 20 wpi & $22 \mathrm{wpi}$ & 24 wpi & 26 wpi & $28 \mathrm{wpi}$ \\
\hline & 1077 & - & - & - & - & - & - & - & $\mathrm{N} / \mathrm{A}$ & $\mathrm{N} / \mathrm{A}$ & $\mathrm{N} / \mathrm{A}$ & $\mathrm{N} / \mathrm{A}$ & N/A & N/A & N/A & $\mathrm{N} / \mathrm{A}$ \\
\hline & 1079 & - & - & - & - & - & - & - & $\mathrm{N} / \mathrm{A}$ & $\mathrm{N} / \mathrm{A}$ & $\mathrm{N} / \mathrm{A}$ & $\mathrm{N} / \mathrm{A}$ & $\mathrm{N} / \mathrm{A}$ & N/A & $\mathrm{N} / \mathrm{A}$ & $\mathrm{N} / \mathrm{A}$ \\
\hline & 1080 & - & - & - & - & - & + & - & N/A & N/A & N/A & N/A & N/A & N/A & N/A & N/A \\
\hline & 1091 & - & - & - & - & - & + & - & N/A & N/A & N/A & N/A & N/A & N/A & N/A & N/A \\
\hline \multirow[t]{5}{*}{ C } & Animal ID & Pre & $2 \mathrm{wpi}$ & $4 \mathrm{wpi}$ & $6 \mathrm{wpi}$ & 8 wpi & $10 \mathrm{wpi}$ & $12 \mathrm{wpi}$ & $14 \mathrm{wpi}$ & $16 \mathrm{wpi}$ & $18 \mathrm{wpi}$ & 20 wpi & $22 \mathrm{wpi}$ & $24 \mathrm{wpi}$ & $26 \mathrm{wpi}$ & 28 wpi \\
\hline & 1130 & - & - & - & - & + & - & - & - & - & - & - & $\mathrm{N} / \mathrm{A}$ & N/A & N/A & N/A \\
\hline & 1131 & - & - & - & - & - & - & - & - & - & - & - & $\mathrm{N} / \mathrm{A}$ & N/A & N/A & $\mathrm{N} / \mathrm{A}$ \\
\hline & 1132 & - & - & - & - & - & - & - & - & - & - & - & $\mathrm{N} / \mathrm{A}$ & N/A & $\mathrm{N} / \mathrm{A}$ & $\mathrm{N} / \mathrm{A}$ \\
\hline & 1133 & - & - & + & - & - & - & - & - & - & - & - & $\mathrm{N} / \mathrm{A}$ & N/A & N/A & $\mathrm{N} / \mathrm{A}$ \\
\hline \multirow[t]{5}{*}{ D } & Animal ID & Pre & $2 \mathrm{wpi}$ & $4 \mathrm{wpi}$ & $6 \mathrm{wpi}$ & $8 \mathrm{wpi}$ & $10 \mathrm{wpi}$ & $12 \mathrm{wpi}$ & $14 \mathrm{wpi}$ & $16 \mathrm{wpi}$ & $18 \mathrm{wpi}$ & $20 \mathrm{wpi}$ & $22 \mathrm{wpi}$ & $24 \mathrm{wpi}$ & $26 \mathrm{wpi}$ & $28 \mathrm{wpi}$ \\
\hline & 1073 & - & + & + & - & - & + & + & - & - & - & - & - & - & - & - \\
\hline & 1075 & - & + & + & - & - & - & - & - & - & - & - & - & - & - & - \\
\hline & 1076 & - & - & + & + & - & - & - & - & - & - & - & - & - & - & - \\
\hline & 1082 & - & - & - & - & - & - & 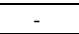 & - & - & - & - & - & - & - & - \\
\hline
\end{tabular}

Figure 4 PCR data for the presence of Map in feces for all Map-exposed animals by weeks post-inoculation (wpi), including 4 (A), 12 (B), 20 (C), and 28 (D). Feces collected before inoculation and then at 2-week intervals following inoculation until euthanasia, as described above. Data are shown as positive (+, light grey) or negative (-). Time points not measured are marked N/A and shaded dark grey. 
occasions. In one animal (calf ID 1073), intermittent shedding of Map in the feces was detected.

\section{Serum ELISA}

ELISA detecting Map-specific serum antibodies at the time of euthanasia in Map-exposed calves is shown as $\mathrm{S} / \mathrm{P}$ ratios in Table 3. Briefly, sera from all calves were negative by ELISA for Map-specific antibodies at the termination points of the study, except for a single calf from the 28 wpi group with an S/P ratio of 0.461 . This calf was classified as suspect based on the manufacturers recommendation. Control animals all had no detectable Mapspecific serum antibodies.

\section{Animal infection status}

In the 4, 12, and 20 wpi groups, all Map-exposed calves were confirmed to have Map infection, based on detection of Map by PCR and/or ZN staining in at least one tissue segment. All but one of these calves (1131, $20 \mathrm{wpi}$ ) were confirmed to be Map infected based on PCR findings in multiple tissues, or PCR findings alongside visual detection of Map by ZN staining. However, at 28 wpi, two calves (1076 and 1082) tested negative for Map in all tissue segments by both PCR and ZN staining and are thus classified as resilient. One of these calves (1082) had mild sterile granulomatous inflammation in three tissue segments, while the other calf (1076) lacked histologic evidence for Map-induced inflammation in all tissues.

Table 3 Map-specific serum ELISA results

\begin{tabular}{llll}
\hline $\begin{array}{l}\text { Infection group } \\
\text { (wpi) }\end{array}$ & Animal ID & S/P ratio & Result \\
\hline 4 & 1115 & 0.077 & - \\
& 1116 & 0.029 & - \\
& 1117 & 0.125 & - \\
& 1120 & 0.062 & - \\
12 & 1077 & 0.025 & - \\
& 1079 & 0.031 & - \\
& 1080 & 0.045 & - \\
& 1091 & 0.021 & - \\
20 & 1130 & 0.06 & - \\
& 1131 & 0.181 & - \\
& 1132 & 0.067 & - \\
& 1133 & 0.061 & - \\
& 1073 & 0.391 & - \\
& 1075 & 0.461 & - \\
& 1076 & 0.086 &
\end{tabular}

a Denotes a result of "suspect" by commercial serum ELISA.

\section{Discussion}

It is widely assumed that on endemic Map-infected farms the Map exposure rate is high, yet only a small number of exposed animals ever show evidence of infection or disease, though experimental evidence has documented a high rate of transmission between exposed and susceptible animals $[5,6,11]$. The question of why Map persists and progresses in some individual animals while others do not remains unanswered. The purpose of this study was to examine persistence of Map within tissues of calves following direct experimental intestinal inoculation. Based on our previous work, we hypothesized that injection of a large measured dose of Map directly into the Peyer's patches of the distal ileum would induce localized and persistent intestinal Map infection, similar to naturally occurring subclinical JD. We also hypothesized that given the route of Map exposure the model could be useful for studying the progression of subclinical to clinical JD.

Map-exposed animals in this study were examined for evidence of localized Map persistence within the tissue using multiple diagnostic tests that are frequently employed for diagnosis of naturally-occurring JD in the field. These data were then used to estimate Map persistence, based on both direct (detection of the pathogen by PCR and ZN staining in intestine and draining lymph nodes collected during post-mortem examination) and indirect (patterns of fecal Map shedding, granulomatous enteritis, and serological responses) evidence. A major finding in this model was that in the 28 wpi group, $50 \%$ (2/4) of the Map-exposed animals had no detectable Map in the small intestine or draining ileocecal lymph node tissues. Based on the infection status classifications defined above, these animals could reasonably be classified as resilient (no evidence for persistent Map tissue infection following direct injection of a large known dose of viable Map). The idea of resilience or resistance to Map infection is not new and is based on significant experimental and clinical evidence [27, 29-32]. However, the majority of work on the subject of resilience has utilized oral infection models, or naturally-infected animals, where resilience may be at least in part attributable to prevention of Map uptake across the mucosal barrier. In the present study, mucosal uptake was bypassed through direct injection of Map into the Peyer's patch rich region of the distal ileum, and this effectively removes mucosal uptake as a factor in understanding persistence in tissue and pathogenesis of early Map infection in a calf model. This approach thus adds significant data supporting the idea that with respect to the pathogenesis of the Map in calves, resilience to Map infection is due, at least in part, to host factors following tissue infection with Map. 
In our study, calves examined at 28 wpi had a wide variation in the outcome following direct Map inoculation. In addition to the two calves classified as resilient, one calf (1075) had evidence for persistent intestinal Map infection, with Map positively identified by PCR in multiple sections of intestine and the draining lymph node. Based on the definitions of paratuberculosis cases, this calf can be considered subclinically diseased, due to mild granulomatous enteritis attributable to Map in three segments of small intestine as well as moderate granulomatous lymphadenitis in the draining ileocecal lymph node [12]. In addition, this particular calf had two instances of fecal Map shedding by direct fecal Map PCR, as well as evidence of serum Map-specific antibodies using a commercial Map ELISA test.

Of the two calves classified in this study as resilient, one had mild granulomatous inflammation in two intestinal tissue segments and the draining lymph node, but with no detectable Map by PCR or ZN staining. Given the previously reported high success of Map infection using direct ileal inoculation (100\% at $12 \mathrm{wpi})$, we believe that this is consistent with residual inflammation due to recovery from intestinal Map infection [13]. Unfortunately, one significant limitation to this study is that individual animals were not sampled repeatedly over the time course of the study to properly establish that these animals were truly initially Map infected. While this Map model has been shown in this and prior studies to reliably induce enteric Map infection, classification of an animal as "recovered" requires repeat tissue sampling within the same animal over time, to show evidence of tissue infection at an earlier time point that has subsequently been cleared from the animal [12]. The other calf classified in this study as resilient was histologically normal at 28 wpi, but had two instances of fecal Map shedding, at four and six wpi. The fecal shedding patterns observed in this study, particularly in the 28 wpi group, are consistent with findings from other experimental infection studies $[11,27,32,33]$. However, it is well accepted that fecal shedding can be a transient phenomenon and thus not truly indicative of tissue Map infection.

Tissue PCR was the most significant measure of Map infection in this study, as statistical analysis identified a significant protective effect of time on the probability of Map PCR positive tissues in each infection group. This suggests that in the present infection model, the prevalence of Map in tissues decreases over time. Another important finding was the translocation of Map from the inoculation site in the distal ileum to the draining ileocecal lymph node. Numerous publications have demonstrated the persistence of Map in lymph nodes, suggesting that the draining lymph nodes are a preferred tissue target for improved sensitivity of diagnostic tests during post-mortem examination [34-38]. Given the route of inoculation in this study, there is a possibility that subserosal injection results in increased draining to the local lymph node, and subsequently dissemination outside of the intestinal tract, though site of infection and draining lymph node are likely to remain key sentinel sites for monitoring persistence of Map within an animal.

The histologic data in this study were less predictive. Neither the mean histologic lesion scores based on H\&E stained tissue segments nor the probability of positive acid-fast bacteria in ZN-stained tissue segments showed any significant differences between groups, as an effect of time. This is likely due to both the low sample size of the study, as well as the generally low mean histologic lesion scores, and number of AFB detected in each infection group.

There is often a question of relevance of the direct inoculation model compared to an oral infection model, and how they relate to natural Map infection. Specifically, the subserosal injection utilized in this infection model may show disproportionate delivery of Map to the submucosa, which may result in altered host responses, and thus not indicative of natural infection. Our histologic examination of the tissue included examination of the submucosa and subserosa, and we observed lesions attributable to Map predominantly within the lamina propria, which is consistent with natural infection. Our data examining Map persistence after direct intestinal Map inoculation over 7 months are directly comparable to a recent study by Begg et al. where Map persistence was examined by intestinal biopsy and then post-mortem examination over a several year period after oral exposure to Map [32].

Taken together, this study provides experimental evidence of resilience to Map infection following direct inoculation of the bacteria into the distal small intestine, considered the primary site of Map infection in natural disease. These data suggest that early localized tissue clearance of Map occurs first from the intestinal tract, then from the draining lymph node. The varied outcomes following Map exposure in this study show similarities with patterns of Map-induced disease observed in the oral model and during natural exposure in endemic herds, but in a much shorter period of time. Consequently, further investigation is required examining host-pathogen interactions in Map infection, and how these factors relate to Map persistence, and resilience to infection observed within this experimental model.

\section{Abbreviations}

AFB: acid fast bacilli; CFU: colony forming units; H\&E: hematoxylin and eosin; JD: Johne's disease; Map: Mycobacterium avium subspecies 
paratuberculosis; S/P: sample:positive control ratio; wpi: weeks post-inoculation; ZN: Ziehl-Neelsen.

\section{Competing interests}

The authors declare that they have no competing interests.

\section{Authors' contributions}

KJS, BLP: Study and experimental design, data collection, data analysis. MMB: Data collection. All authors read and approved the final manuscript.

\section{Acknowledgements}

This work could not be completed without the support of the staff of the University of Guelph animal isolation facility, central animal facility, and Ponsonby dairy research station. We would also like to thank the undergraduate and DVM students who volunteered their time assisting with sample collection and processing work.

\section{Availability of data and materials}

All data generated or analysed during the current study are included in this published article.

\section{Funding}

Funding for this research was provided by the Ontario Ministry of Agriculture, Food, and Rural Affairs (OMAFRA), as a tier one research Grant (Production systems, UofG2011-1077).

\section{Publisher's Note}

Springer Nature remains neutral with regard to jurisdictional claims in published maps and institutional affiliations.

\section{Received: 20 April 2018 Accepted: 18 June 2018}

Published online: 13 July 2018

\section{References}

1. Sweeney RW, Collins MT, Koets AP, McGuirk SM, Roussel AJ (2012) Paratuberculosis (Johne's disease) in cattle and other susceptible species. J Vet Intern Med 26:1239-1250

2. Sweeney RW (2011) Pathogenesis of paratuberculosis. Vet Clin North Am Food Anim Pract 27:537-546

3. Magombedze G, Ngonghala CN, Lanzas C, Lanzas C (2013) Evaluation of the "Iceberg Phenomenon" in Johne's disease through mathematical modelling. PLoS One 8:e76636

4. McKenna SLB, Keefe GP, Tiwari A, VanLeeuwen J, Barkema HW (2006) Johne's disease in Canada part II: disease impacts, risk factors, and control programs for dairy producers. Can Vet J 47:1089-1099

5. Tiwari A, VanLeeuwen JA, McKenna SLB, Keefe GP, Barkema HW (2006) Johne's disease in Canada: part I: clinical symptoms, pathophysiology, diagnosis, and prevalence in dairy herds. Can Vet J 47:874-882

6. Lombard JE (2011) Epidemiology and economics of paratuberculosis. Vet Clin N Am Food Anim Pract 27:525-535

7. Schukken YH, Whitlock RH, Wolfgang D, Grphn Y, Beaver A, VanKessel J, Zurakowski M, Mitchell R (2015) Longitudinal data collection of Mycobacterium avium subspecies paratuberculosis infections in dairy herds: the value of precise field data. Vet Res 46:65

8. Ott SL, Wells SJ, Wagner BA (1999) Herd-level economic losses associated with Johne's disease on US dairy operations. Prev Vet Med 40:179-192

9. Kralik P, Pribylova-Dziedzinska R, Kralova A, Kovarcik K, Slana I (2014) Evidence of passive faecal shedding of Mycobacterium avium subsp. paratuberculosis in a Limousin cattle herd. Vet J 201:91-94

10. Pillars RB, Grooms DL, Kaneene JB (2009) Longitudinal study of the distribution of Mycobacterium avium subsp. paratuberculosis in the environment of dairy herds in the Michigan Johne's disease control demonstration herd project. Can Vet J 50:1039-1046

11. Corbett CS, De Buck J, Orsel K, Barkema HW (2017) Fecal shedding and tissue infections demonstrate transmission of Mycobacterium avium subsp. paratuberculosis in group-housed dairy calves. Vet Res 48:27
12. Whittington RJ, Begg DJ, de Silva K, Purdie AC, Dhand NK, Plain KM (2017) Case definition terminology for paratuberculosis (Johne's disease). BMC Vet Res 13:328

13. Plattner BL, Chiang Y-W, Roth JA, Platt R, Huffman E, Zylstra J, Hostetter JM (2011) Direct inoculation of Mycobacterium avium subspecies paratuberculosis into ileocecal Peyer's patches results in colonization of the intestine in a calf model. Vet Pathol 48:584-592

14. Magombedze G, Eda S, Ganusov VV (2014) Competition for antigen between Th1 and Th2 responses determines the timing of the immune response switch during Mycobaterium avium subspecies paratuberulosis infection in ruminants. PLoS Comput Biol 10:e1003414

15. Facciuolo A, Kelton DF, Mutharia LM (2013) Novel secreted antigens of Mycobacterium paratuberculosis as serodiagnostic biomarkers for Johne's disease in cattle. Clin Vaccine Immunol 20:1783-1791

16. Facciuolo A, Gonzalez-Cano P, Napper S, Griebel PJ, Mutharia LM (2016) Marked differences in mucosal immune responses induced in ileal versus jejunal Peyer's patches to Mycobacterium avium subsp. paratuberculosis secreted proteins following targeted enteric infection in young calves. PLoS One 11:e0158747

17. Li Z, You Q, Ossa F, Mead P, Quinton M, Karrow NA (2016) Assessment of yeast Saccharomyces cerevisiae component binding to Mycobacterium avium subspecies paratuberculosis using bovine epithelial cells. BMC Vet Res 12:42

18. Baquero MM, Plattner BL (2016) Bovine WC1+ $\gamma \delta$ T lymphocytes modify monocyte-derived macrophage responses during early Mycobacterium avium subspecies paratuberculosis infection. Vet Immunol Immunopathol 170:65-72

19. Baquero MM, Plattner BL (2017) Bovine peripheral blood WC1+ and WC1 negy $\delta$ T lymphocytes modulate monocyte-derived macrophage effector functions during in vitro Mycobacterium avium subspecies paratuberculosis infection. Cell Immunol 315:34-44

20. Hostetter JM, Steadham EM, Haynes JS, Bailey TB, Cheville NF (2002) Cytokine effects on maturation of the phagosomes containing Mycobacteria avium subspecies paratuberculosis in $\mathrm{J} 774$ cells. FEMS Immunol Med Microbiol 34:127-134

21. Waters WR, Miller JM, Palmer MV, Stabel JR, Jones DE, Koistinen KA, Steadham EM, Hamilton MJ, Davis WC, Bannantine JP (2003) Early induction of humoral and cellular immune responses during experimental Mycobacterium avium subsp. paratuberculosis infection of calves. Infect Immun 71:5130-5138

22. Rusk RA, Palmer MV, Waters WR, McGill JL (2017) Measuring bovine $\gamma \delta T$ cell function at the site of Mycobacterium bovis infection. Vet Immunol Immunopathol 193-194:38-49

23. Begg DJ, O'Brien R, Mackintosh CG, Griffin JFT (2005) Experimental infection model for Johne's disease in sheep. Infect Immun 73:5603-5611

24. Fernández M, Benavides J, Castaño P, Elquezabal N, Fuertes M, Munoz M, Royo M, Ferreras MC, Perez V (2017) Macrophage subsets within granulomatous intestinal lesions in bovine paratuberculosis. Vet Pathol 54:82-93

25. Subharat S, Shu D, Wedlock DN, Price-Carter M, de Lisle GW, Luo D, Collins DM, Buddle BM (2012) Immune responses associated with progression and control of infection in calves experimentally challenged with Mycobacterium avium subsp. paratuberculosis. Vet Immunol Immunopathol 149:225-236

26. Zhang MZ, Zhang S (2011) An efficient DNA extraction method for polymerase chain reaction-based detection of Mycobacterium avium subspecies paratuberculosis in bovine fecal samples. J Vet Diagn Invest 23:41-48

27. de Silva K, Plain K, Purdie A, Begg D, Whittington R (2018) Defining resilience to mycobacterial disease: characteristics of survivors of ovine paratuberculosis. Vet Immunol Immunopathol 195:56-64

28. Bates D, Machler M, Bolker BM, Walker SC (2015) Fitting linear mixedeffects models using Ime4. J Stat Softw 67:1-48

29. Dennis MM, Reddacliff LA, Whittington RJ (2011) Longitudinal study of clinicopathological features of Johne's disease in sheep naturally exposed to Mycobacterium avium subspecies paratuberculosis. Vet Pathol 48:565-575

30. Buergelt C, Williams B, Monif G (2004) Spontaneous clinical regression of Johne's disease in a Holstein cow: a case report. Intern J Appl Res Vet Med 2:126-129 
31. Koets AP, Adugna G, Janss LL, van Weering HJ, Kalis $C H$, Wentink $G H$, Rutten VP, Schukken YH (2000) Genetic variation of susceptibility to Mycobacterium avium subsp. paratuberculosis infection in dairy cattle. J Dairy Sci 83:2702-2708

32. Begg DJ, Plain KM, de Silva K, Gurung R, Gunn A, Purdie AC, Whittington RJ (2018) Immunopathological changes and apparent recovery from infection revealed in cattle in an experimental model of Johne's disease using lyophilised culture of Mycobacterium avium subspecies paratuberculosis. Vet Microbiol 219:53-62

33. Mortier RAR, Barkema HW, Orsel K, Wolf R, De Buck J (2014) Shedding patterns of dairy calves experimentally infected with Mycobacterium avium subspecies paratuberculosis. Vet Res 45:71

34. Wu CW, Livesey M, Schmoller SK, Manning EJB, Steinberg H, Davis WC, Hamilton MJ, Talaat AM (2007) Invasion and persistence of Mycobacterium avium subsp. paratuberculosis during early stages of Johne's disease in calves. Infect Immun 75:2110-2119
35. Koets A, Rutten V, Hoek A, van Mil F, Muller K, Bakker D, Gruys E, van Eden W (2002) Progressive bovine paratuberculosis is associated with local loss of CD4+ T cells, increased frequency of $\gamma \delta T$ cells, and related changes in T-cell function. Infect Immun 70:3856-3864

36. Wells JE, Bosilevac JM, Kalchayanand N, Arthur TM, Shackelford SD, Wheeler TL, Koohmaraie M (2009) Prevalence of Mycobacterium avium subsp. paratuberculosis in ileocecal lymph nodes and on hides and carcasses from cull cows and fed cattle at commercial beef processing plants in the United States. J Food Prot 72:1457-1462

37. Murray HL, Yabsley MJ, Keel MK, Manning EJ, Wilmers TJ, Corn JL (2014) Persistence of Mycobacterium avium subspecies paratuberculosis in endangered Florida Key deer and Key deer habitat. J Wildl Dis 50:349-353

38. Merkal RS, Whipple DL, Sacks JM, Snyder GR (1987) Prevalence of Mycobacterium paratuberculosis in ileocecal lymph nodes of cattle culled in the United States. J Am Vet Med Assoc 190:676-680
Ready to submit your research? Choose BMC and benefit from:

- fast, convenient online submission

- thorough peer review by experienced researchers in your field

- rapid publication on acceptance

- support for research data, including large and complex data types

- gold Open Access which fosters wider collaboration and increased citations

- maximum visibility for your research: over $100 \mathrm{M}$ website views per year

At BMC, research is always in progress.

Learn more biomedcentral.com/submissions 